\title{
Analytical Solutions for Vertical Flow in Unsaturated, Rooted Soils with Variable Surface Fluxes
}

Fasong Yuan

Cleveland State University, f.yuan06@csuohio.edu

Zhiming Lu

Los Alamos National Laboratory, zhiming@lanl.gov

Follow this and additional works at: https://engagedscholarship.csuohio.edu/scibges_facpub

Part of the Biology Commons

How does access to this work benefit you? Let us know!

Publisher's Statement

Co-publisher with American Society of Agronomy and Crop Science Society of America.

\section{Recommended Citation}

Yuan, F., and Z. Lu. 2005. Analytical Solutions for Vertical Flow in Unsaturated, Rooted Soils with Variable Surface Fluxes. Vadose Zone J. 4:1210-1218. doi:10.2136/vzj2005.0043

This Article is brought to you for free and open access by the Biological, Geological, and Environmental Sciences Department at EngagedScholarship@CSU. It has been accepted for inclusion in Biological, Geological, and Environmental Faculty Publications by an authorized administrator of EngagedScholarship@CSU. For more information, please contact library.es@csuohio.edu. 


\title{
Analytical Solutions for Vertical Flow in Unsaturated, Rooted Soils with Variable Surface Fluxes
}

\author{
Fasong Yuan and Zhiming Lu*
}

\begin{abstract}
Analytical solutions to Richards' equation have been derived to describe the distribution of pressure head, water content, and fluid flow for rooted, homogeneous soils with varying surface fluxes. The solutions assume that (i) the constitutive relations for the hydraulic conductivity and water content as function of the pressure head are exponential, (ii) the initial water content distribution is a steady-state distribution, and (iii) the root water uptake is a function of depth. Three simple forms of root water uptake are considered, that is, uniform, stepwise, and exponential functional forms. The lower boundary of the rooted soil profile studied is a water table, while at the upper boundary time-dependent surface fluxes are specified, either infiltration or evaporation. Application of the Kirchhoff transformation allows us to linearize Richards' equation and derive exact solutions. The steady-state solution is given in a closed form and the transient solution has the form of an infinite series. The solutions are used to simulate the hydraulic behavior of the rooted soils under different conditions of root uptake and surface flux. The restricted assumptions for the solutions may limit the applicability, but the solutions are relatively flexible and easy to implement compared to other analytical and numerical schemes. The analytical solutions provide a reliable and convenient means for evaluating the accuracy of various numerical schemes, which usually require sophisticated algorithms to overcome convergence and mass balance problems.
\end{abstract}

Ince the EARly studies by Philip (1957) and Gardner (1958), the search for analytical solutions to Richards' (1931) flow equation has yielded a variety of mathematical expressions describing the water content distribution in unsaturated zones (Raats, 2001; Raats et al., 2002). Many analytical solutions describe the downward water movement that is induced by infiltration (Philip, 1969; Warrick et al., 1985; Srivastava and Yeh, 1991; Warrick et al., 1991; Ross and Parlange, 1994; Chen et al., 2003). In reality, other processes, such as plant root water uptake and capillary rise etc., also affect the vertical water movement. However, analytical solutions capable of handling the abovementioned three processes simultaneously are scarce.

Analytically solving Richards' equation with various initial and boundary conditions is challenging because of the highly nonlinear relationship between the hydraulic conductivity and the pressure head. Linear or quasilinear approximations are usually needed to facilitate mathemat-

Fasong Yuan, Agric. Research and Extension Center, Texas A\&M Univ., El Paso, TX 79927, USA. Zhiming Lu, Hydrology, Geochemistry, and Geology Group (EES-6), Los Alamos National Lab., Los Alamos, NM 87545. Received 16 Mar. 2005. *Corresponding author (zhiming@lanl.gov). ical formulation. Based on the nature of the linearization and/or approximation of Richards' equation, the existing analytical solutions may be divided into two classes; one uses exponential constitutive relationships (Gardner, 1958; Warrick, 1975; Lomen and Warrick, 1978; Srivastava and Yeh, 1991; Basha, 2000; Chen et al., 2003), the other uses power law forms (Van Genuchten, 1980; Broadbridge and White, 1988; Ross and Parlange, 1994; Warrick and Parkin, 1995; Kim et al., 1996; Hogarth and Parlange, 2000). Analytically solving Richards' equation with a sink term describing root water uptake is extremely difficult because the uptake is related to a range of variables, such as root depth, water content, and salinity (Feddes and Raats, 2004). Existing analytical solutions to this problem usually assume that root water uptake is an exponential function of root depth to ease the mathematical derivation (Raats, 1974; Rubin and Or, 1993; Basha, 2000; Schoups and Hopmans, 2002). In reality, many modelers rely on numerical approximation schemes to simulate the hydraulic behavior of the unsaturated soils with root water uptake (Neuman et al., 1975; Feddes et al., 1976; Van Dam and Feddes, 2000). However, numerical solutions usually require sophisticated algorithms to overcome convergence and mass conservation problems (Milly, 1985; Celia et al., 1990; Van Dam and Feddes, 2000). Although subject to more restrictive assumptions, analytical solutions are relatively easy to implement and thus provide an effective means for evaluating the accuracy of numerical schemes. Warrick (1974) proposed steady-state solutions to Richards' equation for exponential and discrete sink functions of depth. Lomen and Warrick (1978) developed transient solutions for the case that the sink term is a sequence of time-dependent functions of depth. The complex form of their solutions limits their applicability. Here we develop a new set of analytical solutions to transient flow for rooted soils with time-dependent varying surface fluxes. The initial water contents are assumed to be in steady state. Exponential water retention and hydraulic conductivity relationships are used to linearize Richards' equation, and the sink term is assumed to be a function of depth. Lastly, analytical solutions to transient flow in rooted soils with varying surface fluxes are used and discussed through illustrative examples.

\section{MATHEMATICAL FORMULATION}

For one-dimensional flow in unsaturated soils with root water uptake, the flow equation can be written as

$\frac{\partial}{\partial z}\left[K(\psi)\left(\frac{\partial \psi}{\partial z}+1\right)\right]-S(z)=C(\psi) \frac{\partial \psi}{\partial t}, \quad 0 \leq z \leq L$

subject to an initial condition 


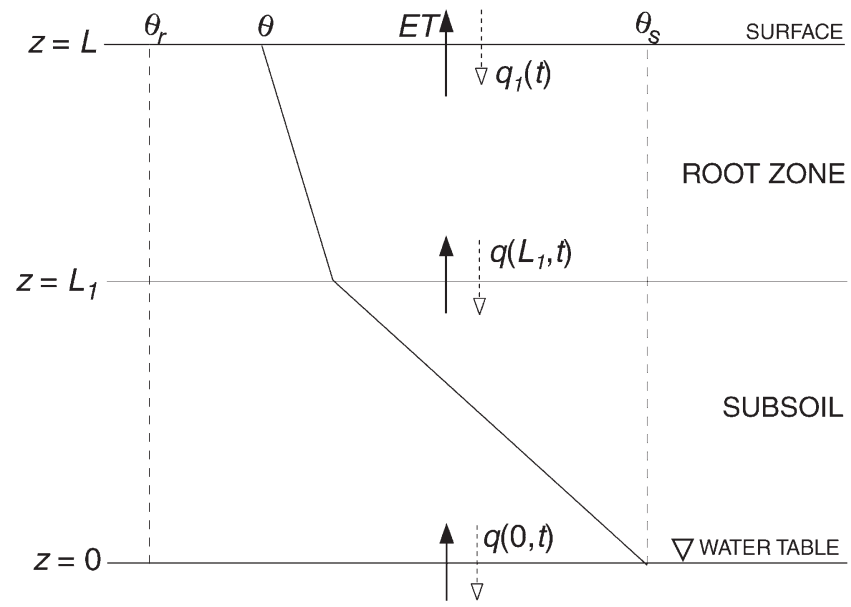

Fig. 1. Schematic of hypothetical water content $(\theta)$ distribution in unsaturated soils. $\theta_{s}$ is the water content at saturation, $\theta_{\mathrm{r}}$ is the residual water content, ET denotes evapotranspiration through root water uptake, $q_{1}$ is time-dependent varying surface flux, and $q(z, t)$ is water flow below soil surface. Note that both ET and $q$ are positive upward.

$$
\psi(z, 0)=\psi_{0}(z)
$$

and boundary conditions

$$
\begin{aligned}
\psi(0, t) & =\psi_{1} \\
{\left[K(\psi)\left(\frac{\partial \psi}{\partial z}+1\right)\right]_{z=L} } & =-q_{1}(t)
\end{aligned}
$$

where $\psi$ is the pressure head $(\mathrm{L}), K(\psi)$ is the hydraulic conductivity $\left(\mathrm{LT}^{-1}\right), C(\psi)=d \theta / d \psi$ is the differential water capacity $\left(\mathrm{L}^{-1}\right), \theta$ is the volumetric water content, $S$ represents the root water uptake $\left(\mathrm{T}^{-1}\right), z$ is the vertical coordinate pointing upward (L) (see Fig. 1$), \psi_{0}$ is the initial pressure head specified in the domain $(\mathrm{L}), \psi_{1}$ is the prescribed pressure head at the lower boundary (L), $q_{1}(t)$ is the time-dependent flux at the upper boundary (negative flux for infiltration, $\mathrm{LT}^{-1}$ ), and $t$ is the time (T).

For mathematical convenience, we choose exponential models to describe the dependence of the hydraulic conductivity and the water content on the pressure head, that is, $K(\psi)=K_{\mathrm{s}} \mathrm{e}^{\alpha \psi}$ and $\theta=\theta_{\mathrm{r}}+\left(\theta_{\mathrm{s}}-\theta_{\mathrm{r}}\right) \mathrm{e}^{\alpha \psi}$. The latter leads to $C(\psi)=\mathrm{d} \theta / \mathrm{d} \psi=\alpha\left(\theta_{\mathrm{s}}-\theta_{\mathrm{r}}\right) \mathrm{e}^{\alpha \psi}$. Here $K_{\mathrm{s}}$ is the hydraulic conductivity $\left(\mathrm{L} \mathrm{T}^{-1}\right)$ at saturation, $\theta_{s}$ is the water content at saturation $\left(\mathrm{L}^{3} \mathrm{~L}^{-3}\right)$, and $\theta_{r}$ is the residual water content $\left(\mathrm{L}^{3} \mathrm{~L}^{-3}\right)$, and $\alpha$ is the soil pore-size distribution parameter $\left(\mathrm{L}^{-1}\right)$, which represents the reduction rate of the hydraulic conductivity and water content as $\psi$ is usually negative in unsaturated soils. Using the Kirchhoff transformation (Gardner, 1958; Lu and Zhang, 2004).

$$
\Phi(z, t)=\int_{-\infty}^{\psi} K(\psi) \mathrm{d} \psi=\frac{K(\psi)}{\alpha}
$$

Richards' equation can be linearized as

$$
\frac{\partial^{2} \Phi}{\partial z^{2}}+\alpha \frac{\partial \Phi}{\partial z}-S(z)=\frac{1}{D} \frac{\partial \Phi}{\partial t}
$$

with initial and boundary conditions

$$
\begin{aligned}
\Phi(z, 0)=\Phi_{0}(z) & =\frac{K_{\mathrm{s}}}{\alpha} \exp \left[\alpha \psi_{0}(z)\right] \\
\Phi(0, t)=\Phi_{1}(t) & =\frac{K_{\mathrm{s}}}{\alpha} \exp \left(\alpha \psi_{1}\right) \\
{\left[\frac{\partial \Phi}{\partial z}+\alpha \Phi\right]_{z=L} } & =-q_{1}(t)
\end{aligned}
$$

where $\Phi$ is called the matrix flux potential $\left(\mathrm{L}^{2} \mathrm{~T}^{-1}\right), D=$ $K_{\mathrm{s}} /\left\{\alpha\left(\theta_{\mathrm{s}}-\theta_{\mathrm{r}}\right)\right\}$ is the soil moisture diffusivity $\left(\mathrm{L}^{2} \mathrm{~T}^{-1}\right)$.

In this study, we assume that the initial soil water distribution is a steady state rather than a uniform profile. In the following sections, we will derive the steady-state solution and then use it as an initial condition for a transient solution.

\section{Steady-State Solutions}

The steady-state matric flux potential $\Phi_{\mathrm{s}}$ satisfies the ordinary differential equation:

$$
\frac{\mathrm{d}^{2} \Phi_{\mathrm{s}}}{\mathrm{d} z^{2}}+\alpha \frac{\mathrm{d} \Phi_{\mathrm{s}}}{\mathrm{d} z}-S(z)=0
$$

and the boundary conditions

$$
\begin{aligned}
\Phi_{\mathrm{s}}(0) & =\frac{K_{\mathrm{s}}}{\alpha} \exp \left(\alpha \psi_{1}\right) \\
{\left[\frac{\mathrm{d} \Phi_{\mathrm{s}}}{\mathrm{d} z}+\alpha \Phi_{\mathrm{s}}\right]_{z=L} } & =-q_{0}
\end{aligned}
$$

where $q_{0}$ is the surface flux at the time $t=0$. Let

$$
\Phi_{\mathrm{s}}=\phi-\frac{q_{0}+K_{\mathrm{s}} \exp \left(\alpha \psi_{1}\right)}{1+\alpha L} z+\frac{K_{\mathrm{s}}}{\alpha} \exp \left(\alpha \psi_{1}\right)
$$

then the steady-state equation and its boundary conditions become

$$
\begin{array}{r}
\frac{\mathrm{d}^{2} \phi}{\mathrm{d} z^{2}}+\alpha \frac{\mathrm{d} \phi}{\mathrm{d} z}-[S(z)+A]=0 \\
\phi(0)=0 \\
{\left[\frac{\mathrm{d} \phi}{\mathrm{d} z}+\alpha \phi\right]_{z=L}=0}
\end{array}
$$

where $A=\alpha\left(q_{0}+K_{\mathrm{s}} \mathrm{e}^{\alpha \psi_{1}}\right) /(1+\alpha L)$. The solution to Eq. [14] to [16] can be expressed formally as

$$
\phi(z)=\int_{0}^{L} G(z, x)[S(x)+A] \mathrm{d} x
$$

where the Green function $G(z, x)$ for this case is defined as

$G(z, s)= \begin{cases}\frac{\exp (-\alpha z)}{\alpha}[1-\exp (\alpha s)] & 0 \leq s \leq z \leq L \\ \frac{1}{\alpha}[\exp (-\alpha z)-1] & 0 \leq z \leq s \leq L\end{cases}$

Combining Eq. [13], [17], and [18], one has

$$
\begin{aligned}
\Phi_{\mathrm{s}}(z)=\frac{K_{\mathrm{s}} \exp \left[\alpha\left(\psi_{1}-z\right)\right]}{\alpha} & +\frac{q_{0}}{\alpha}[\exp (-\alpha z)-1] \\
& +\int_{0}^{L} G(z, x) S(x) \mathrm{d} x
\end{aligned}
$$

Equation [19] gives a general solution to steady verti- 
cal flow problems. For any given uptake term $S$ as a function of $z$, the corresponding steady-state solution for the matrix flux potential $\Phi_{\mathrm{s}}$ can be derived by carrying out the integral in Eq. [19]. For complicated functional forms of the uptake term $S$, the integral in Eq. [19] may need to be evaluated numerically. However, for some particular uptake functions, the steady-state solution can be derived analytically through Eq. [19] as follows.

\section{Uniform Root Uptake}

In the simplest case, the root uptake term is a constant $S(z)=S_{0}>0$ for all $0 \leq z \leq L$. Integrating Eq. [19] yields

$$
\begin{gathered}
\Phi_{\mathrm{s}}(z)=\frac{K_{\mathrm{s}} \exp \left[\alpha\left(\psi_{1}-z\right)\right]}{\alpha}+\frac{q_{0}}{\alpha}[\exp (-\alpha z)-1]+ \\
\frac{S_{0}}{\alpha^{2}}[(\alpha L+1) \exp (-\alpha z)-\alpha(L-z)-1]
\end{gathered}
$$

For $z=0$, the matrix flux potential $\Phi_{\mathrm{s}}(0)=K_{\mathrm{s}} \exp \left(\alpha \psi_{1}\right) / \alpha$ , which is independent of the root uptake $S$ and of course consistent with Eq. [8] and [11].

\section{Step Functions}

In general, the depth of the rooted zone is less than that of the vadose zone; that is, the root uptake takes place only in the upper portion of the vadose zone. In this case, the root uptake may be approximated by $S(z)=S_{0} H(z-$ $\left.L_{1}\right)$, where $H\left(z-L_{1}\right)$ is the Heaviside function defined as $H\left(z-L_{1}\right)=0$ for $0 \leq z \leq L_{1}$ and $H\left(z-L_{1}\right)=1$ for $L_{1} \leq z \leq L$. Integrating Eq. [19] yields the steadystate solution

$$
\Phi_{\mathrm{s}}(z)= \begin{cases}\frac{K_{\mathrm{s}} \exp \left[\alpha\left(\psi_{1}-z\right)\right]}{\alpha}+\frac{q_{0}}{\alpha}[\exp (-\alpha z)-1]+ \\ \frac{S_{0}\left(L-L_{1}\right)}{\alpha}[\exp (-\alpha z)-1] & 0 \leq z \leq L_{1} \\ \frac{K_{\mathrm{s}} \exp \left[\alpha\left(\psi_{1}-z\right)\right]}{\alpha}+\frac{q_{0}}{\alpha}[\exp (-\alpha z)-1]+ & L_{1} \leq z \leq L \\ \frac{S_{0}\left[\alpha\left(L-L_{1}\right)+\exp \left(\alpha L_{1}\right)\right]}{\alpha^{2}} \exp (-\alpha z)- \\ \frac{S_{0}}{\alpha^{2}}[\alpha(L-z)+1] & \end{cases}
$$

It is easy to check that both the steady-state solution $\Phi_{s}$ and its first-order derivative are continuous at $z=$ $L_{1}$. In the case that $L_{1}=0$, that is, uniform root uptake in the entire domain, from the second part of the solution we can verify that the above solution reduces to Eq. [20]. On the other hand, if $L_{1}=L$, that is, no uptake at all, from the first part of this solution, we can easily see that the term with uptake disappears.

More generally, if the uptake function $S(z)$ is defined as a piecewise step function on $0=z_{0} \leq z_{1} \leq \cdots \leq z_{n}=L$ as $S(z)=\sum_{i=1}^{n} S_{i} H\left(z-z_{i-1}\right) H\left(z_{i}-z\right)$, the steady-state solution can be written as, for any $z_{k-1} \leq z \leq z_{k}$,

$$
\begin{aligned}
& \Phi_{\mathrm{s}}(z)=\frac{K_{\mathrm{s}} \exp \left[\alpha\left(\psi_{1}-z\right)\right]}{\alpha}+\frac{q_{0}}{\alpha}[\exp (-\alpha z)-1]+ \\
& \frac{\exp (-\alpha z)}{\alpha} \sum_{j=1}^{n} S_{j}\left(z_{j}-z_{j-1}\right)-\frac{1}{\alpha} \sum_{j=k+1}^{n} S_{j}\left(z_{j}-z_{j-1}\right)- \\
& \frac{\exp (-\alpha z)}{\alpha^{2}} \sum_{j=1}^{k-1} S_{j}\left[\exp \left(\alpha z_{j}\right)-\exp \left(\alpha z_{j-1}\right)\right]- \\
& \frac{S_{k}}{\alpha^{2}}\left\{\alpha\left(z_{k}-z\right)+1-\exp \left[\alpha\left(z_{k-1}-z\right)\right]\right.
\end{aligned}
$$

This particular case is of interest in connection with observed root length or root mass in individual layers.

\section{Exponential Uptake}

The distribution function of root uptake may be expressed in an exponential form (Raats, 1974; Rubin and Or, 1993; Schoups and Hopmans, 2002), $S(z)=$ $S_{0} \exp [\beta(z-L)]$ where $S_{0}$ is the maximum uptake at the land surface $\left(\mathrm{T}^{-1}\right)$ and $\beta$ is a constant $\left(\mathrm{L}^{-1}\right)$ representing the rate of reduction in root uptake. Carrying out the integral in Eq. [19] yields

$$
\begin{aligned}
& \Phi_{\mathrm{s}}(z)=\frac{K_{\mathrm{s}} \exp \left[\alpha\left(\psi_{1}-z\right)\right]}{\alpha}+\frac{q_{0}}{\alpha}[\exp (-\alpha z)-1]+ \\
& \frac{S_{0}\{\exp [\beta(z-L)]-\exp (-\alpha z-\beta L)+\exp (-\alpha z)-1\}}{\alpha \beta}- \\
& \frac{S_{0}\{\exp [\beta(z-L)]-\exp (-\alpha z-\beta L)\}}{\alpha(\alpha+\beta)}
\end{aligned}
$$

The steady-state pressure head and water content can be computed from $\psi=(1 / \alpha) \ln \left(\alpha \Phi_{\mathrm{s}} / K_{\mathrm{s}}\right)$ and $\theta=\theta_{\mathrm{r}}+$ $\alpha\left(\theta_{\mathrm{s}}-\theta_{\mathrm{r}}\right) \Phi_{\mathrm{s}} / K_{\mathrm{s}}$.

In case with $L$ approaching infinity, Eq. [23] becomes

$$
\Phi_{\mathrm{s}}(Z)=-\frac{q_{0}}{\alpha}-\frac{S_{0}[\alpha+\beta-\alpha \exp (-\beta Z)]}{\alpha \beta(\alpha+\beta)}
$$

where $Z=L-z$ is the depth below the land surface. Given the assumption that hydraulic conductivity is a linear function of water content $(\theta)$ or matrix flux potential $\left(\Phi_{s}\right)$, Eq. [24] has the similar form of the solution given by Raats (1976, Eq. [16]).

\section{Transient Solutions}

The steady-state solution $\Phi_{\mathrm{s}}$ is now taken as the initial condition $\Phi_{0}$ for the transient problem Eq. [6] through [9]. Taking the Laplace transformation, we have the ordinary differential equation

$$
\frac{\mathrm{d}^{2} \tilde{\Phi}}{\mathrm{d} z^{2}}+\alpha \frac{\mathrm{d} \tilde{\Phi}}{\mathrm{d} z}-\frac{s}{D} \tilde{\Phi}+\frac{\Phi_{\mathrm{s}}}{D}-\frac{S}{s}=0
$$

with boundary conditions

$$
\begin{aligned}
\tilde{\Phi}(0) & =\frac{\Phi_{1}(z)}{s} \\
{\left[\frac{\mathrm{d} \tilde{\Phi}}{\mathrm{d} z}+\alpha \tilde{\Phi}\right]_{z=L} } & =-\tilde{q}(s)
\end{aligned}
$$

where $s$ is the Laplace-transform complex variable, $\tilde{\Phi}=$ 

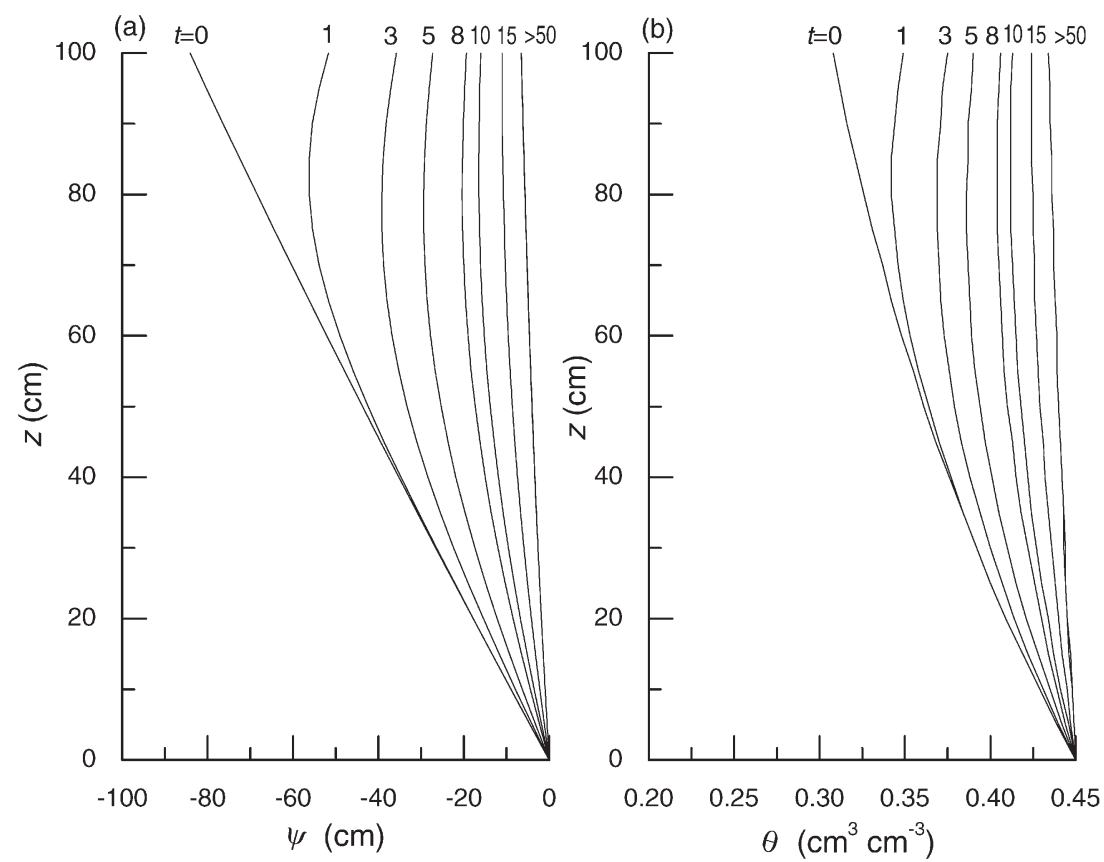

Fig. 2. Wetting profiles of (a) pressure head and (b) water content for soils without root water uptake $\left(\alpha=0.01 \mathrm{~cm}^{-1}\right)$.

$\boldsymbol{L}(\Phi)$, and $\tilde{q}_{1}=\boldsymbol{L}\left(q_{1}\right)$. Solving Eq. [25] to [27] and taking the inverse of the Laplace transformation, we finally obtain the matrix flux potential $\Phi$ for transient flow (see Appendix A for details)

$$
\begin{gathered}
\Phi(z, t)=\Phi_{\mathrm{s}}(z)+8 D \exp \left[\frac{\alpha(L-z)}{2}\right] \\
\sum_{n=1}^{\infty} \frac{\left(\lambda_{n}^{2}+\frac{\alpha^{2}}{4}\right) \sin \left(\lambda_{n} L\right) \sin \left(\lambda_{n} z\right)}{2 \alpha+\alpha^{2} L+4 L \lambda_{n}^{2}} G(t) \\
G(t)=\int_{0}^{t}\left[q_{0}-q_{1}(\tau)\right] \exp \left[-D\left(\lambda_{n}^{2}+\frac{\alpha^{2}}{4}\right)(t-\tau)\right] \mathrm{d} \tau
\end{gathered}
$$

where $\lambda_{\mathrm{n}}$ is the $n$th positive root of equation $\sin (\lambda L)+$ $(2 \lambda / \alpha) \cos (\lambda L)=0$. Note that the transient part in Eq. [28] does not depend on the root uptake, which is due to the assumption that the uptake term $S(z)$ is timeindependent. The flux water flow below the land surface at any time can be derived from $q(z, t)=\mathrm{d} \Phi / \mathrm{d} z+\alpha \Phi$ and is given by

$$
\begin{aligned}
& q(z, t)=q_{0}+\int_{z}^{L} S(x) \mathrm{d} x-8 D \exp \left[\frac{\alpha(L-z)}{2}\right] \\
& \sum_{n=1}^{\infty} \frac{\left(\lambda_{n}^{2}+\frac{\alpha^{2}}{4}\right) G(t) \sin \left(\lambda_{n} L\right)}{2 \alpha+\alpha^{2} L+4 L \lambda_{n}^{2}}\left[\frac{\alpha}{2} \sin \left(\lambda_{n} z\right)+\lambda_{n} \cos \left(\lambda_{n} z\right)\right]
\end{aligned}
$$

In the case that $q_{1}$ is a constant, Eq. [28] can be simplified to

$$
\begin{gathered}
\Phi(z, t)=\Phi_{\mathrm{s}, \mathrm{q}_{1}}(z)-8\left(q_{0}-q_{1}\right) \exp \left[\frac{\alpha(L-z)}{2}\right] \\
\sum_{n=1}^{\infty} \frac{\sin \left(\lambda_{n} L\right) \sin \left(\lambda_{n} z\right)}{2 \alpha+\alpha^{2} L+4 L \lambda_{n}^{2}} \exp \left[-D\left(\lambda_{n}^{2}+\frac{\alpha^{2}}{4}\right) t\right]
\end{gathered}
$$

where $\Phi_{\mathrm{s}, \mathrm{q}_{1}}$ is the final steady-state solution of the transient problem with surface flux $q_{1}$ and can be obtained on replacing $q_{0}$ in $\Phi_{\mathrm{s}}$ by $q_{1}$. Correspondingly, Eq. [30] can be simplified to

$$
\begin{gathered}
q(z, t)=q_{1}+\int_{z}^{L} S(x) \mathrm{d} x+4 \alpha\left(q_{0}-q_{1}\right) \exp \left[\frac{\alpha(L-z)}{2}\right] \\
\sum_{n=1}^{\infty} \frac{\sin \left(\lambda_{n} L\right)\left[\sin \left(\lambda_{n} z\right)+2 \lambda_{n} \cos \left(\lambda_{n} z\right)\right]}{2 \alpha+\alpha^{2} L+4 \lambda_{n}^{2} L} \exp \left[-D\left(\lambda_{n}^{2}+\frac{\alpha^{2}}{4}\right) t\right]
\end{gathered}
$$

\section{ILLUSTRATIVE EXAMPLES AND DISCUSSION}

In this section, we will discuss the analytical solutions through numerical examples, in which we compute the distributions of the pressure head, water content, and water flux across a $100-\mathrm{cm}$ soil profile with the lower boundary confined by the water table (Fig. 1). The water content at saturation and residual water content of the soils are assumed to be 0.45 and $0.20 \mathrm{~cm}^{3} \mathrm{~cm}^{-3}$ (Srivastava and Yeh, 1991). The hydraulic conductivity at saturation is taken as $1.0 \mathrm{~cm} \mathrm{~h}^{-1}$. The initial water content profile is assumed to be a steady-state profile with a surface influx of $0.1 \mathrm{~cm} \mathrm{~h}^{-1}$; that is, $q_{0}=-0.1$. Both constant and varying surface fluxes are considered for the upper boundary conditions.

\section{Constant Surface Flux}

In this case we assume that a constant infiltration of $0.9 \mathrm{~cm} \mathrm{~h}^{-1}$ (i.e., $q_{1}=-0.9$ ) occurs and lasts for at least a few days. The transient distribution of the pressure head and the water content can be computed based on the solution (31) and the exponential hydraulic parameter models. Figures 2 and 3 show the computed distri- 

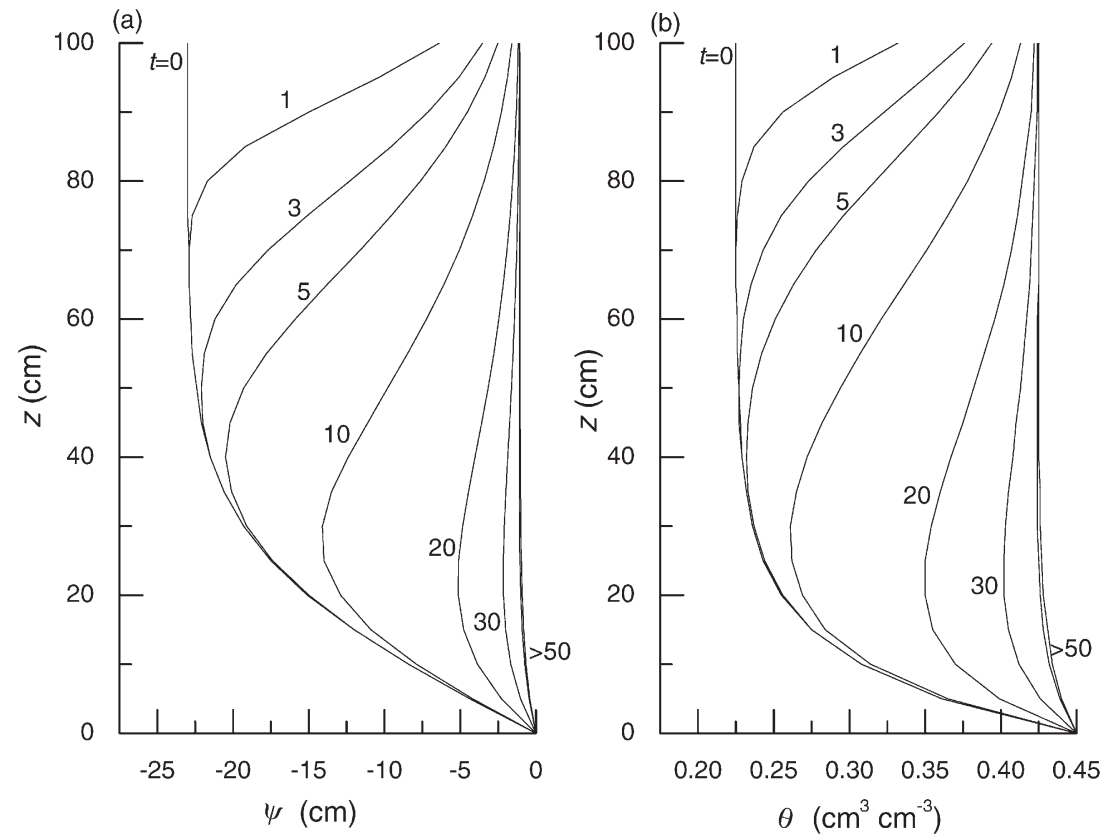

Fig. 3. Wetting profiles of (a) pressure head and (b) water content for soils without root water uptake $\left(\alpha=0.1 \mathrm{~cm}^{-1}\right)$.

butions of the pressure head and the water content for homogeneous soils with $\alpha=0.01 \mathrm{~cm}^{-1}$ and $\alpha=0.1 \mathrm{~cm}^{-1}$, respectively, for a period of $50 \mathrm{~h}$. Note that the root uptake is ignored in the two examples. The calculated results are exactly the same as those of Srivastava and Yeh (1991). Both the pressure head and water content profiles are similar in shape because of the similar form of the exponential hydraulic parameter model used. The soil water moves faster in the soils with $\alpha=0.01 \mathrm{~cm}^{-1}$, but the time needed to reach the steady state is nearly the same (about $50 \mathrm{~h}$ ) due to the same surface boundary condition considered. This is especially the case near the soil surface where the soil water content approaches the steady state faster than further down in the soil.

In the presence of root water uptake, we consider a rooted soil profile with a maximum root depth of $40 \mathrm{~cm}$ (i.e., $L_{1}=60 \mathrm{~cm}$ in Fig. 1) and assume that the distribution of root water uptake can be described by the Heaviside function. The maximum water uptake at the land surface $\left(S_{0}\right)$ is taken as $0.02 \mathrm{~h}^{-1}$ for $\alpha=0.01 \mathrm{~cm}^{-1}$, and $0.0025 \mathrm{~h}^{-1}$ for $\alpha=0.1 \mathrm{~cm}^{-1}$. Figures $4 \mathrm{a}$ and $4 \mathrm{~b}$ show changes in the water content distribution for such rooted
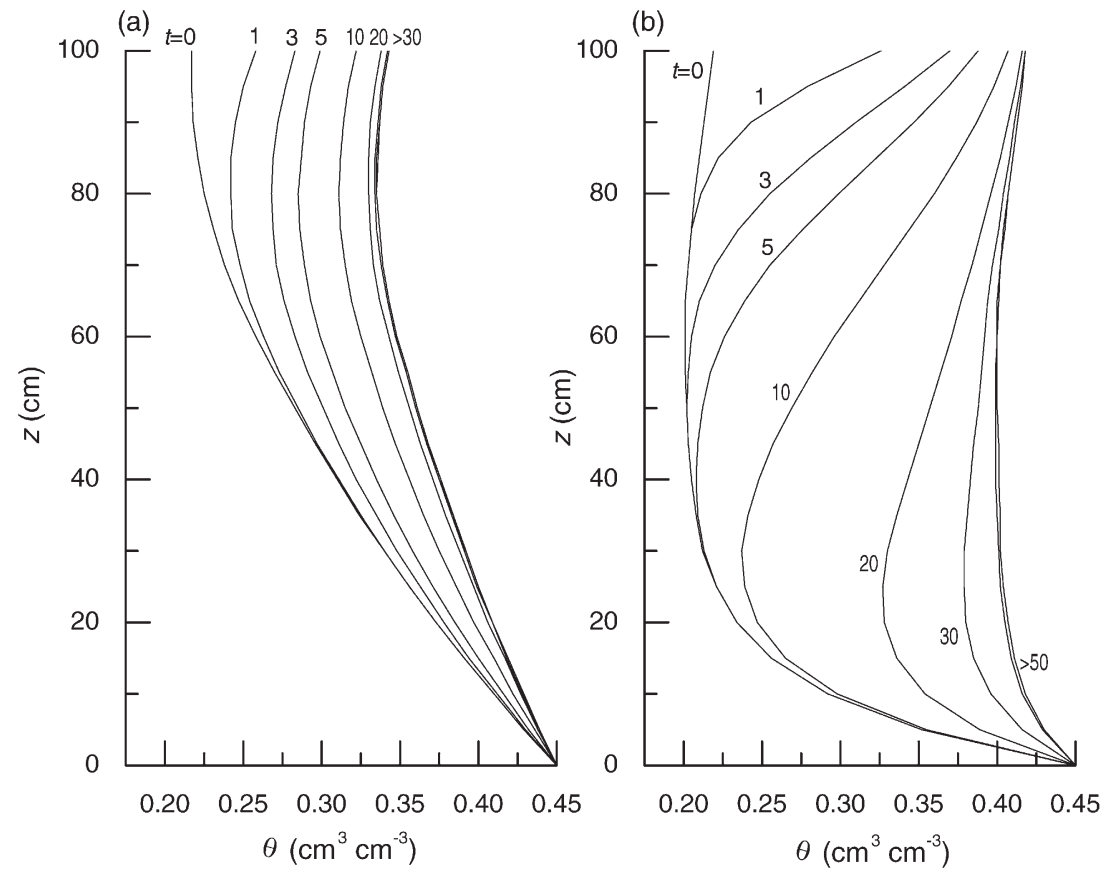

Fig. 4. Comparison of wetting profiles in rooted soils under constant surface flux $\left(q_{1}=-0.9 \mathrm{~cm} \mathrm{~h}^{-1}\right)$. (a) $\alpha=0.01 \mathrm{~cm}^{-1}, S_{0}=0.02 \mathrm{~h}^{-1}$. (b) $\alpha=$ $0.1 \mathrm{~cm}^{-1}$ and $S_{0}=0.0025 \mathrm{~h}^{-1}$. 
(a)
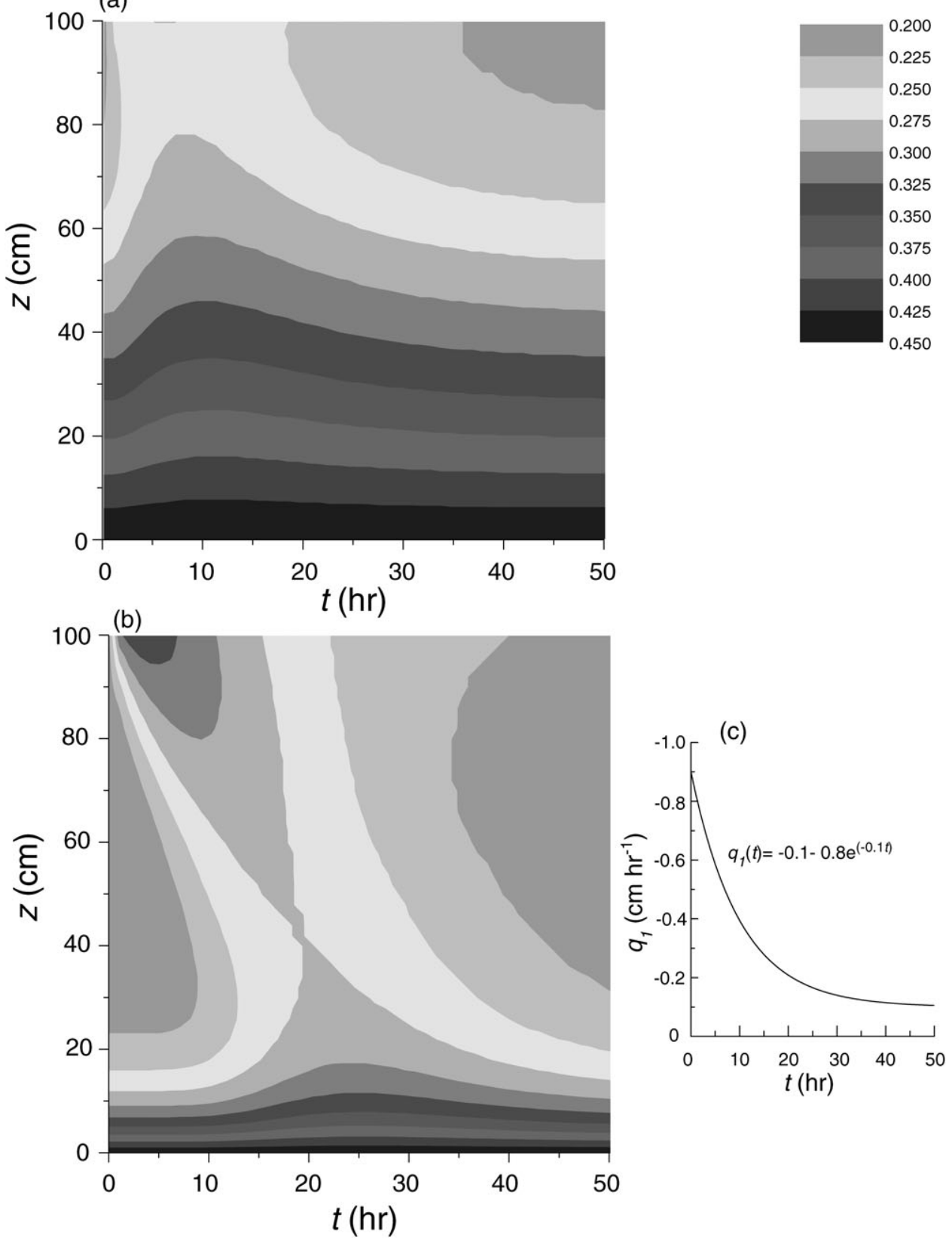

Fig. 5. Comparison of soil water distribution in rooted soils under varying surface fluxes $q_{1}(t)$. (a) $\alpha=0.01 \mathrm{~cm}^{-1}$ and $S_{0}=0.02 \mathrm{~h}^{-1}$. (b) $\alpha=$ $0.1 \mathrm{~cm}^{-1}$ and $S_{0}=0.0025 \mathrm{~h}^{-1}$. (c) Exponential surface input function.

soils during a period over 30 to $50 \mathrm{~h}$. The initial water content profile for the rooted soils with $\alpha=0.01 \mathrm{~cm}^{-1}$ is much drier than that without root uptake (Fig. 2b). The initial moisture profile approaches a new steady state approximately $30 \mathrm{~h}$ after the beginning of the increase in infiltration rate. On the other hand, the water content profile of the rooted soils with $\alpha=0.1 \mathrm{~cm}^{-1}$ is similar to that without root uptake (Fig. 3b), as the root uptake component is relatively small, which accounts for $\sim 11 \%$ of the infiltration.

\section{Time-Dependent Surface Flux}

In reality, the upper boundary conditions always vary with time as a result of agricultural practices and weather forcing, for example, irrigation, rainfall and evaporation, etc. Here we consider that the surface flux is an exponentially decaying function of time, namely $q_{1}(t)=q_{0}+$ $\delta \exp (k t)$ where $\delta=-0.8 \mathrm{~cm} \mathrm{~h}^{-1}$ and $k=-0.1 \mathrm{~h}^{-1}$. This simple surface flux model allows $q_{1}$ to approach $q_{0}$ when $t$ becomes sufficiently large (Fig. $5 \mathrm{c}$ ). The moisture contents at any time and depth are computed through Eq. [28] using the exponential surface flux model and the results are presented in Fig. 5a and $5 \mathrm{~b}$ for the rooted soils. Both of the rooted soils receive the same amount of water from the upper boundary, but exhibit rather different patterns of the water content distributions. The soil profile with $\alpha=0.01 \mathrm{~cm}^{-1}$ is on average wetter than the soil with $\alpha=0.1 \mathrm{~cm}^{-1}$ even though the amount of 
(a)

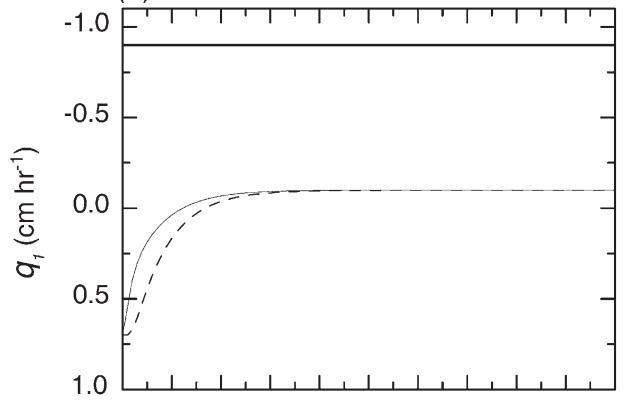

(b)

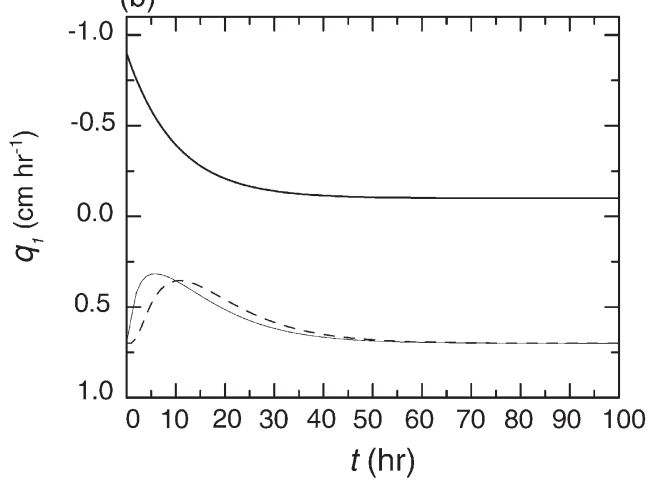

(c)
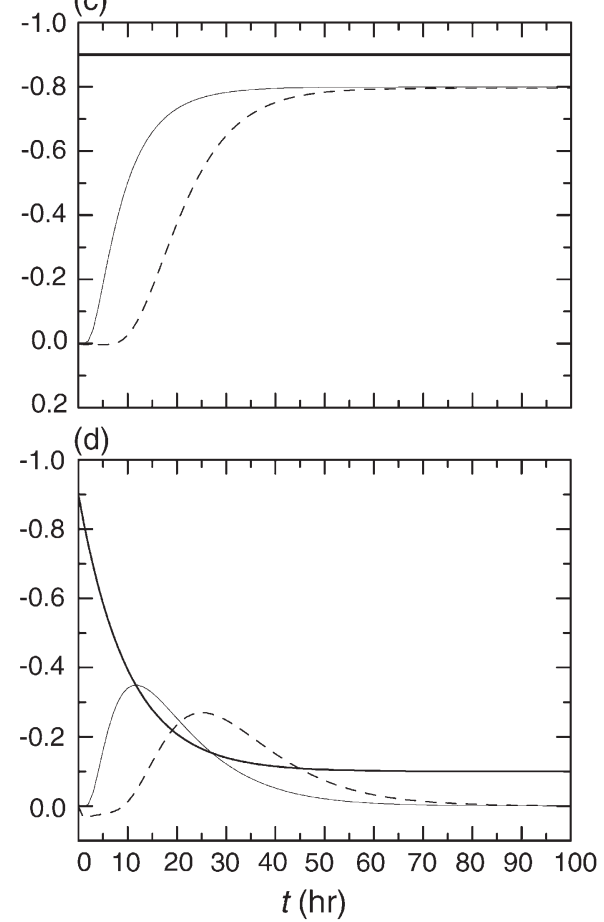

Fig. 6. Temporal development of water flows. (a) $\alpha=0.01 \mathrm{~cm}^{-1}, S_{0}=0.02 \mathrm{~h}^{-1}$, and $k=0$. (b) $\alpha=0.01 \mathrm{~cm}^{-1}, S_{0}=0.02 \mathrm{~h}^{-1}$, and $k=-0.1$. (c) $\alpha=0.1 \mathrm{~cm}^{-1}, S_{0}=0.0025 \mathrm{~h}^{-1}$, and $k=0$. (d) $\alpha=0.1 \mathrm{~cm}^{-1}, S_{0}=0.0025 \mathrm{~h}^{-1}$, and $k=-0.1$. Infiltration $\left(q_{1}\right)$ is in thick solid curves, flow at interface between root zone and subsoil $\left(q_{2}\right)$ in thin solid curves, and flow near the water table $\left(q_{3}\right)$ in dashed curves. Note that $k$ is a constant in $q_{1}(t)=q_{0}+\delta \exp (k t), \delta=-0.8 \mathrm{~cm} \mathrm{~h}^{-1}$.

water loss through root uptake is larger than that received from infiltration. This is because the larger root water uptake in the soil with $\alpha=0.01 \mathrm{~cm}^{-1}$ favors the capillary rise that brings water from the water table into root zones. On the other hand, the impact from the rapid change in $q_{1}$ on the soil moisture content is much deeper in the soil with $\alpha=0.1 \mathrm{~cm}^{-1}$ and the response time increases with the increasing depth.

To evaluate the transient water flow in response to changes in the surface flux, we use Eq. [30] to compute the flow $\left(q_{2}\right)$ at the interface between the root zone and subsoil and the flow at the water table $\left(q_{3}\right)$ (Fig. 6). In the rooted soil with $\alpha=0.01 \mathrm{~cm}^{-1}$ (Fig. 6a and $6 \mathrm{~b}$ ) the difference between $q_{2}$ and $q_{3}$ is relatively small. Both $q_{2}$ and $q_{3}$ approach $-0.1 \mathrm{~cm} \mathrm{~h}^{-1}$ for the constant surface flux and $0.7 \mathrm{~cm} \mathrm{~h}^{-1}$ for the exponentially decaying surface flux when $t>50 \mathrm{~h}$. Note that the positive values of $q_{2}$ and $q_{3}$ suggest that water moves upward, that is, capillary rise. In the cases of constant surface flux (Fig. 6a and 6c) the absolute value of $q_{2}$ is always not less than that of $q_{3}$, while in the cases of varying surface flux (Fig. $6 \mathrm{~b}$ and $6 \mathrm{~d}$ ) the absolute value of $q_{2}$ is not always greater than that of $q_{3}$. It is easy to check the mass is conservative in all the cases. Additionally, the response time of $q_{2}$ is usually shorter than that of $q_{3}$. The time lag is likely associated with the hydraulic conductivity.

\section{SUMMARY AND CONCLUSIONS}

We solved Richards' equation for water flow in unsaturated, rooted soils under time-dependent varying upper boundary conditions. The analytical solutions are based on assumptions that (i) the hydraulic conductivity and water content are exponential functions of the pressure head, (ii) the initial water contents are in steady state, and (iii) the distribution of root water uptake is a function of depth. Both steady state and transient solutions are given and discussed through illustrative examples. Equation [28] gives an alternative single form of the one-dimensional solutions of Basha (2000, their Eq. [24], [26], [38], and [51]). The analytical solutions are validated by comparing the computed pressure head and water content using other analytical solutions (Srivastava and Jim Yeh, 1991). The analytical solutions are useful to predict the vertical distribution of the water content and the water flux. This analytical solution is not applicable in cases where the exponential hydraulic parameter model is not appropriate. An implicit assumption of a shallow water table with a fixed depth is needed for the solutions, that is, water table does not rise with infiltration or fall with root water uptake. Another limitation of the analytical solutions is imposed by the assumption related to the sink term of root water uptake. In reality, the distribution of root uptake is not only a function of depth but also related to other factors, for example, water content, salinity, and even plant physiological parameters. Nevertheless, the analytical solutions provide an additional tool for validating and/or checking the accuracy of numerical schemes.

\section{APPENDIX A}

In equations [25]-[27], let $\tilde{\Phi}=\phi+\Phi_{\mathrm{s}} / s$, we obtain equations for the new variable $\phi$ 


$$
\begin{aligned}
\frac{\mathrm{d}^{2} \phi}{\mathrm{d} z^{2}}+\alpha \frac{\mathrm{d} \phi}{\mathrm{d} z}-\frac{s}{D} \phi & =0 \\
\phi(0) & =0 \\
{\left[\frac{\mathrm{d} \phi}{\mathrm{d} z}+\alpha \phi\right]_{z=L} } & =\frac{q_{0}}{s}-\tilde{q}_{1}(s)
\end{aligned}
$$

The characteristic equation for Eq. [A1] is

$$
\lambda^{2}+\alpha \lambda-\frac{s}{D}=0
$$

and its two solutions are

$$
\lambda_{1,2}=\frac{\alpha}{2}+\sqrt{\frac{s}{D}+\frac{\alpha^{2}}{4}}=-\frac{\alpha}{2} \pm \Delta
$$

The general solution of $\phi$ can be written as

$$
\phi(z)=C_{1} \exp \left(\lambda_{1} z\right)+C_{2} \exp \left(\lambda_{2} z\right)
$$

where $C_{1}$ and $C_{2}$ are constants to be determined. Using boundary conditions [A2] and [A3], one can solve these two constants

$$
C_{1}=-C_{2}=\frac{\exp (\alpha L / 2)}{2} \frac{q_{0} / s-\tilde{q}_{1}(s)}{\frac{\alpha}{2} \sinh (\Delta L)+\Delta \cosh (\Delta L)}
$$

and

$\phi(z)=\exp \left[\frac{\alpha(L-z)}{2}\right] \frac{\left[q_{0} / s-\tilde{q}_{1}(s)\right] \sinh (\Delta z)}{\frac{\alpha}{2} \sinh (\Delta L)+\Delta \cosh (\Delta L)}$

The Laplace transformed variable $\tilde{\Phi}$ can be written as

$$
\tilde{\Phi}(z)=\frac{\Phi_{s}(z)}{s}+\exp \left[\frac{\alpha(L-z)}{2}\right] \frac{\left[q_{0} / s-\tilde{q}_{1}(s)\right] \sinh (\Delta z)}{\frac{\alpha}{2} \sinh (\Delta L)+\Delta \cosh (\Delta L)}
$$

The solution of Eq. [6] to [9] is given as

$$
\Phi(z, t)=\Phi_{s}(z)+\exp \left[\frac{\alpha(L-z)}{2}\right]\left[q_{0}-q_{1}(t)\right] * \boldsymbol{L}^{-1}[F(s)]
$$

where the symbol * represents convolution, and

$$
F(s)=\frac{\sinh (\Delta z)}{\frac{\alpha}{2} \sinh (\Delta L)+\Delta \cosh (\Delta L)}
$$

Finding the inverse of Laplace transformation of function $F(s)$ is equivalent to finding the sum of all residues of $\mathrm{e}^{s t} F(s)$ at poles of $F(s)$, at which the denominator of $F(s)$ is zero; that is,

$$
\frac{\alpha}{2} \sinh (\Delta L)+\Delta \cosh (\Delta L)=0
$$

We get all poles of $F(s)$ by setting $\Delta=i \lambda_{n}$, or $s=$ $-D\left(\lambda_{n}^{2}+\frac{\alpha^{2}}{4}\right)$, where $\lambda_{n}$ satisfies

$$
\sin \left(\lambda_{n} L\right)+\frac{2 \lambda_{n}}{\alpha} \cos \left(\lambda_{n} L\right)=0
$$

Since the residue of $\mathrm{e}^{s t} F(s)$ at $s=-D\left(\lambda_{n}^{2}+\frac{\alpha^{2}}{4}\right)$ is

$$
\begin{aligned}
& \operatorname{Res}\left\{\exp (s t) F(s),-D\left(\lambda_{n}^{2}+\frac{\alpha^{2}}{4}\right)\right\}= \\
& 8 D \frac{\left(\lambda_{n}^{2}+\frac{\alpha^{2}}{4}\right) \sin \left(\lambda_{n} L\right) \sin \left(\lambda_{n} z\right)}{2 \alpha+\alpha^{2} L+4 L \lambda_{n}^{2}} \exp \left[-D\left(\lambda_{n}^{2}+\frac{\alpha^{2}}{4}\right) t\right]
\end{aligned}
$$

the inverse transformation of $F(s)$ can be derived as $L^{-1}\{F(s)\}=$

$$
8 D \sum_{n=1}^{\infty} \frac{\left(\lambda_{n}^{2}+\frac{\alpha^{2}}{4}\right) \sin \left(\lambda_{n} L\right) \sin \left(\lambda_{n} z\right)}{2 \alpha+\alpha^{2} L+4 L \lambda_{n}^{2}} \exp \left[-D\left(\lambda_{n}^{2}+\frac{\alpha^{2}}{4}\right) t\right]
$$

Finally, we solve the Kirchhoff transformed variable $\Phi$

$$
\begin{aligned}
& \Phi(z, t)=\Phi_{\mathrm{s}}(z)+8 D \exp \left[\frac{\alpha(L-z)}{2}\right] \sum_{n=1}^{\infty} \\
& \frac{\left(\lambda_{n}^{2}+\frac{\alpha^{2}}{4}\right) \sin \left(\lambda_{n} L\right) \sin \left(\lambda_{n} z\right)}{\alpha^{2} L+2 \alpha+4 L \lambda_{n}^{2}} \\
& \int_{0}^{t}\left[q_{0}-q_{1}(\tau)\right] \exp \left[-D\left(\lambda_{n}^{2}+\frac{\alpha^{2}}{4}\right)(t-\tau)\right] \mathrm{d} \tau
\end{aligned}
$$

\section{REFERENCES}

Basha, H.A. 2000. Multidimensional linearized nonsteady infiltration toward a shallow water table. Water Resour. Res. 36:2567-2573.

Broadbridge, P., and I. White. 1988. Constant rate rainfall infiltration: A versatile nonlinear model. 1. Analytic solution. Water Resour. Res. 24:145-154.

Celia, M.A., E.T. Bouloutas, and R.L. Zarba. 1990. A general massconservative numerical solution for the unsaturated flow equation. Water Resour. Res. 26:1483-1496.

Chen, J.M., Y.C. Tan, and C.H. Chen. 2003. Analytical solutions of onedimensional infiltration before and after ponding. Hydrol. Proc. 17:815-822.

Feddes, R.A., P. Kowalik, K. Kolinska-Malinka, and H. Zaradny. 1976. Simulation of field water uptake by plants using a soil water dependent root extraction function. J. Hydrol. (Amsterdam) 31:13-26.

Feddes, R.A., and P.A.C. Raats. 2004. Parameterizing the soil-waterplant root system, p. 95-141. In R.A. Feddes et al. (ed.) Unsaturated-zone modeling: Progress, challenges and applications. Wageningen UR Frontis Series. Kluwer Academic Publ., Dordrecht, The Netherlands.

Gardner, W.R. 1958. Some steady-state solutions of the unsaturated moisture flow equation with application to evaporation from a water table. Soil Sci. 85:228-232.

Hogarth, W.L., and J.Y. Parlange. 2000. Application and improvement of a recent approximate analytical solution of Richards' equation. Water Resour. Res. 36:1965-1968.

Kim, C.P., J.N.M. Stricker, and P.J.J.F. Torfs. 1996. An analytical framework for the water budget of the unsaturated zone. Water Resour. Res. 32:3475-3484.

Lomen, D.O., and A.W. Warrick. 1978. Time-dependent solutions to the one-dimensional linearized moisture flow equation with water extraction. J. Hydrol. (Amsterdam) 39:59-67.

Lu, Z., and D. Zhang. 2004. Analytical solutions to steady state unsatu- 
rated flow in layered, randomly heterogeneous soils via Kirchhoff transformation. Adv. Water Resour. 27:775-784.

Milly, P.C.D. 1985. A mass conservative procedure for time-stepping in models of unsaturated flow. Adv. Water Resour. 8:32-36.

Neuman, S.P., R.A. Feddes, and F. Bresler. 1975. Finite element analysis of two-dimensional flow in soils considering water uptake by roots. I. Theory. Soil Sci. Soc. Am. Proc. 39:224-230.

Philip, J.R. 1957. The theory of infiltration. 4. Sorptivity and algebraic infiltration equations. Soil Sci. 84:257-264.

Philip, J.R. 1969. Theory of infiltration. Adv. Hydrosci. 5:215-296.

Raats, P.A.C. 1974. Steady flows of water and salt in uniform soil profiles with plant roots. Soil Sci. Soc. Am. Proc. 38:717-722.

Raats, P.A.C. 1976. Analytical solutions of a simplified flow equation. Trans. Am. Soc. Agric. Eng. 19:683-689.

Raats, P.A.C. 2001. Developments in soil-water physics since the mid 1960s. Geoderma 100:355-387.

Raats, P.A.C., D.E. Smiles, and A.W. Warrick. 2002. Contributions to environmental mechanics: Introduction. p. 1-28. In P.A.C. Raats et al. (ed.) Environmental mechanics: Water, mass and energy transfer in the biosphere. Am. Geophysical Union, Washington, DC.

Richards, L.A. 1931. Capillary conduction of liquids through porous mediums. Physics 1:318-333.

Ross, P.J., and J.Y. Parlange. 1994. Comparing exact and numerical solutions of Richards' equation for one-dimensional infiltration and drainage. Soil Sci. 157:341-344.

Rubin, Y., and D. Or. 1993. Stochastic modeling of unsaturated flow in heterogeneous soils with water uptake by plant roots: The parallel columns model. Water Resour. Res. 29:619-631.

Schoups, G., and J.W. Hopmans. 2002. Analytical model for vadose zone solute transport with root water and solute uptake. Available at www.vadosezonejournal.org. Vadose Zone J. 1:158-171.

Srivastava, R., and T.C. Jim Yeh. 1991. Analytical solutions for onedimensional, transient infiltration toward the water table in homogeneous and layered soils. Water Resour. Res. 27:753-762.

Van Dam, J.C., and R.A. Feddes. 2000. Numerical simulation of infiltration, evaporation and shallow groundwater levels with the Richards equation. J. Hydrol. 233:72-85.

van Genuchten, M.Th. 1980. A closed-form equation for predicting the hydraulic conductivity of unsaturated soils. Soil Sci. Soc. Am. J. 44:892-898.

Warrick, A.W. 1974. Solution to the one-dimensional linear moisture flow equation with water extraction. Soil Sci. Soc. Am. Proc. 38: 573-576.

Warrick, A.W. 1975. Analytical solutions to the one-dimensional linearized moisture flow equation for arbitrary input. Soil Sci. 120: $79-84$.

Warrick, A.W., A. Islas, and D.O. Lomen. 1991. An analytical solution to Richards' equation for time-varying infiltration. Water Resour. Res. 27:763-766.

Warrick, A.W., D.O. Lomen, and S.R. Yates. 1985. A generalized solution to infiltration. Soil Sci. Soc. Am. J. 49:34-38.

Warrick, A.W., and G.W. Parkin. 1995. Analytical solution for onedimensional drainage: Burgers' and simplified forms. Water Resour. Res. 31:2891-2894. 